\title{
Fibroblast Growth Factor 21 Protects Against High Glucose Induced Cellular Damage and Dysfunction of Endothelial Nitric-Oxide Synthase in Endothelial Cells
}

\author{
Xiao-Mei Wang Shuang-Shuang Song Hang Xiao Pan Gao Xue-Jun Li Liang-Yi Si \\ Department of Geriatrics, Southwest Hospital, Third Military Medical University, Chongqing, China
}

Key Words

FGF21 • Endothelial cell $\bullet$ AMPK $・$ eNOS $\cdot$ High glucose

\begin{abstract}
Aims: Fibroblast growth factor 21 (FGF21) is a powerful endocrine hormone modulating glucose and lipid metabolism and represents a promising drug for type 2 diabetes. The present study was to determine the effect of FGF21 on high glucose-induced damage and dysfunction in endothelial cells. Methods: The protein expression of $\beta$-klotho was examined in human umbilical vein endothelial cell (HUVECs) using immunofluorescence and Western blotting. HUVECs were cultured in medium with normal glucose (NG), high glucose (HG) and HG + FGF21 $(30 \mathrm{nM})$. Cell viability, migration, reactive oxygen species (ROS), malondialdehyde (MDA), superoxide dismutase, nitric oxide (NO) production, intracellular cyclic guanosine monophosphate (cGMP) and endothelial nitric oxide synthase (eNOS) phosphorylation at Ser-1177/Ser633 sites were measured. Results: $\beta$-klotho, the anchor protein of FGF21, is expressed in HUVECs. Administration of FGF21 prevented HG-induced impairment of cell viability, migration, oxidant stress, NO production and intracellular cGMP levels in HUVECs. FGF21 also rescued HG-induced decrease of eNOS phosphorylation at Ser-1177 and Ser-633. HG and FGF21 had no effects on eNOS phosphorylation at Ser-617 and Thr-495. Inhibition of AMP-activated protein kinase (AMPK), but not Akt or $\mathrm{Ca}^{2+} / \mathrm{calmodulin}$-dependent protein kinase II, abolished the protective effect of FGF21 on eNOS phosphorylation at Ser-1177. The protective effect of FGF21 on eNOS phosphorylation at Ser-633 was also abolished by inhibition of AMPK but not by Akt or CAMP-dependent protein kinase A. Conclusion: Our results provide the first evidence that FGF21 protects against high glucose induced cell damage and eNOS dysfunction in an AMPK-dependent manner in HUVECs, and suggest that FGF21 may be a promoting therapeutic agent for vascular complications in diabetes.
\end{abstract}

Copyright (C) 2014 S. Karger AG, Basel 


\section{Cellular Physiology and Biochemistry}

Cell Physiol Biochem 2014;34:658-671

DOI: 10.1159/000363031

Published online: August 13, 2014

(c) 2014 S. Karger AG, Basel

www.karger.com/cpb

Wang et al.: Effect of FGF21 on ECs Under High Glucose Condition

\section{Introduction}

Endothelial dysfunction is a well-accepted marker of vascular injury. The endothelial dysfunction is related with apoptosis [1], autophagy [2,3] and the malfunction of intracellular molecular cascades [4]. Endothelial dysfunction is associated with cardiovascular risk factors and precedes the development of hypertension, atherosclerosis, myocardial infarction and etc. Importantly, recent data suggest that loss of modulatory role of the endothelium could be implicated in the pathogenesis of diabetic vascular complications [5]. A large number of evidence indicates that the endothelial dysfunction is impaired in diabetic animal models and patients [5]. The high levels of blood glucose induces endothelial dysfunction, which is characterized by changes in altered barrier function, increased oxidative stress, inflammatory activation and, most importantly, impairment of endothelium-derived nitric oxide (NO).

Fibroblast growth factors are a family of structurally related polypeptides characterized by a high affinity for heparin [6]. Most FGFs act as paracrine factors diffusing away from their origin tissues and functions on cell growth and differentiation [6, 7]. Fibroblast growth factor 21 (FGF21) is a member of FGFs super family that is reported to be primarily expressed in metabolic organs/tissues such as liver [8]. Unlike most other FGFs, FGF21 is released from liver into blood as a hormone and mediates its biological responses as an extracellular protein by binding to and activating cell surface FGF receptor [9]. In this process, $\beta$-klotho, a transmembrane anchor protein, is required for the activation of FGF21-induced signaling cascade $[9,10]$. $\beta$-klotho enriches in metabolic tissues such as liver and adipose [8].

Recently, FGF21 attracts much attention as a relatively new fasting-responding hormone increasing energy production and improving energy utilization $[11,12]$. It acts as an autocrine factor regulating PPARg activity and glucose uptake $[13,14]$. Moreover, FGF21 protects from glucolipotoxicity and cytokine-induced islet apoptosis, increases islet insulin content, and enhances glucose-induced insulin secretion [15]. FGF21 also regulates lipolysis in white adipose tissue [16]. Meanwhile, the biological functions of FGF21 in non-metabolic tissues have been gradually discovered. FGF21 increases systemic glucocorticoid levels, suppresses physical activity and alters circadian behavior by acting on suprachiasmatic nucleus of the hypothalamus and the dorsal vagal complex of the hindbrain [17]. Moreover, FGF21 modulates female reproduction in response to nutritional challenge by acting on the suprachiasmatic nucleus [18]. Serum FGF21 levels correlates significantly with blood CD4 lymphocyte count and immune recovery in HIV infection [19]. However, the roles of FGF21 in other system are largely unknown yet.

FGF21 is a circulating protein and its serum concentrations are closely associated with metabolic physiology and diseases. Blood FGF21 levels are elevated in impaired glucose tolerance and type 2 diabetes and correlate with muscle and hepatic insulin resistance $[20,21]$. Interestingly, blood FGF21 levels also correlates with blood glucose in diabetic patients $[20,21]$. It is well known that high glucose is a perturbation sufficient to alter the characteristics of vascular biology in diabetes. Thus, the potential effect of blood FGF21 on vascular biology, especially under high glucose condition, is an interesting question. To answer this, we investigated the influence of FGF21 on the biological functions of endothelial cells under high glucose condition. Our results provide the first evidence that FGF21 protects against high glucose-induced damage and regulates endothelial nitric oxide synthase (eNOS) phosphorylation in endothelial cells.

\section{Materials and Methods}

\section{Reagents}

Mouse FGF21 full length protein (catalogue No: ab63277), compound C, nitric oxide (NO) assay were purchased from Abcam (Cambridge, UK). EBM-2 medium was purchased from Lonza (Long Beach, CA, USA). Antibodies against phospho-eNOS-Ser1177 (p-eNOS-Ser1177), phospho-eNOS-Ser633, total-Enos, phosphoAMPK, total-AMPK and tubulin were purchased from Millipore (Milford, MA, USA). Two antibodies against 


\section{Cellular Physiology and Biochemistry}

Cell Physiol Biochem 2014;34:658-671

DOI: $10.1159 / 000363031$

(C) 2014 S. Karger AG, Basel

www.karger.com/cpb

Wang et al.: Effect of FGF21 on ECs Under High Glucose Condition

$\beta$-klotho (R\&D Systems and Santa Cruz Biotechnology) were used in this study. Cy-3 conjugated secondary antibody, KN-93, H-89 and MK-2206 were purchased from Santa Cruz Biotechnology (Santa Cruz, CA, USA). Dichloro-dihydro-fluorescein diacetate (DCFH-DA), 4',6-diamidino-2-phenylindole (DAPI) and M199 culture medium were purchased from Invitrogen (Carslbad, CA, USA). Cell viability assay (Cell Counting Kit8) was purchased from Dojindo Molecular Technologies, Inc. (Kumamoto, Japan). Malondialdehyde (MDA), cyclic guanosine monophosphate (cGMP) and manganese-/copper-zinc- superoxide dismutase (Mn-SOD and $\mathrm{Cu} / \mathrm{Zn}$-SOD) kits were purchased from Cell Biolab (San Diego, CA, USA). Protease inhibitors cocktail and phosphatase inhibitor cocktail were purchased from Pierce Chemical Co. (Rockford, IL, USA). siRNA targeting AMPKa1/2 was purchased from Santa-Cruz Biotechnology (Santa-Cruz, CA, USA).

\section{Cell culture and siRNA transfection}

Human umbilical vein endothelial cells (HUVECs) were purchased from American Type Culture Col- lection (Rockville, MD) and cultured as described [2]. Briefly, cells were grown under M199 medium containing $10 \%$ fetal bovine serum and penicillin $(100 \mathrm{IU} / \mathrm{mL})$ and streptomycin $(100 \mu \mathrm{g} / \mathrm{mL})$ at $37^{\circ} \mathrm{C}$ in a humidified $5 \% \mathrm{CO}_{2}$ atmosphere. The concentration of glucose in this medium is $5.5 \mathrm{mM}$ (normal glucose). To produce high glucose challenge in HUVECs, high gluctose ( $50 \mathrm{mM}$ and $100 \mathrm{mM}$ ) was applied. For FGF21 treatment, PBS-dissolved FGF21 was added into the medium.

Transfection of siRNA was performed using Lipofactamine LTX with PLUS (Invitrogen) as described previously [22,23]. Briefly, cells were grown in six-well plate to $30 \%$ confluence and washed with serum-free medium. About $800 \mu \mathrm{l}$ of serum-free medium were added per well. $100 \mathrm{nM}$ siRNA and $5 \mu \mathrm{l}$ of Lipofactamine (Invitrogen) were mixed and added into $200 \mu \mathrm{l}$ medium. The mixtures was incubated for $30 \mathrm{~min}$ at room temperature and then added into cells for 6 hours. One day after the initial transfection, a second round of transfection was performed in the same way as the previous one. At $72 \mathrm{~h}$ after initial transfection, cells were treated and harvested as indicated.

\section{Immunofluorescence}

Immunofluorescence was performed as described previously [24, 25]. HUVECs were plated on 13$\mathrm{mm}$ glass coverslips and cultured for $24 \mathrm{~h}$ before fixation. The cells were fixed with $4 \%$ paraformaldehyde at room temperature for $30 \mathrm{~min}$, permeabilized with $0.05 \%$ Triton X-100 for $10 \mathrm{~min}$, and immunostained with an anti- $\beta$-klotho antibody. In negative control, normal IgG replaced the anti- $\beta$-klotho antibody. Then, cells were stained by secondary antibody that had been conjugated with Cy3. DNA staining with DAPI was performed at $0.5 \mu \mathrm{g} / \mathrm{ml}$ [26]. All immunofluorescence images were observed on a FV1000 Confocol microscopy (Olympus, Japan).

\section{Western blotting}

Western blotting was performed as described previously $[27,28]$. Briefly, cells were lysed in lysis buffer with protease inhibitors cocktail and phosphatase inhibitor cocktail. Cell lysates were centrifuged at $10,000 \mathrm{~g}$ for $10 \mathrm{~min}$. The supernatants were collected and boiled for $10 \mathrm{~min}$. After determination of protein concentration, equal amounts of proteins $(\sim 30 \mu \mathrm{g})$ were separated by $12 \%$ SDS-PAGE. Blots were transferred to nitrocellulose membrane and incubated overnight at $4{ }^{\circ} \mathrm{C}$ with antibodies against $\beta$-klotho (1:800), p-eNOS-ser1177 (1:400), p-eNOS-ser633 (1:400), t-eNOS (1:1000) and tubulin (1:1000) and followed by corresponding secondary antibodies $(1: 5,000)$. Signals were detected using enhanced chemoluminescence kit (ECL, Amersham, USA).

\section{Cell viability assay}

Cell viability was evaluated by a non-radioactive cell counting kit-8 (CCK-8) assay as described previously [29]. HUVECs were maintained in cultured medium with normal glucose, high glucose and high glucose + FGF21 (30 nM) in 96-well plates. Medium was changed daily. At 24 and 48 hours post treatment, medium was discarded and cells were incubated in CCK-8 solution for $2 \mathrm{~h}$ at the same incubator conditions after which the absorbance was read at $450 \mathrm{~nm}$ with a reference wavelength of $570 \mathrm{~nm}$.

\section{Transwell migration assay}

HUVECs $\left(1 \times 10^{5}\right)$ were placed in the upper chamber of a 24-well transwell migration insert (pore size: $5 \mu \mathrm{m}$ ) with M199 medium in the presence normal glucose, high glucose and high glucose + FGF21 (30 nM). 


\section{Cellular Physiology and Biochemistry}

Cell Physiol Biochem 2014;34:658-671

DOI: $10.1159 / 000363031$

(C) 2014 S. Karger AG, Basel

www.karger.com/cpb

Wang et al.: Effect of FGF21 on ECs Under High Glucose Condition

The lower chamber contained migration medium (EBM-2 medium, 0.5\% BSA, 20\%FBS). After migration for 12 and 24 hours, nonmigrating cells on the upper side of the membrane were removed with a cotton swab [30]. Cells that had migrated and were attached to the lower side were fixed with $10 \%$ formalin and stained with DAPI for 2 min and counted in five different random fields using a fluorescent microscopy [31].

Activity of caspase-3/7

Activity of caspase-3/7 was measured using a fluorimetric assay from Promega (Madison, WI) as described previously $[32,33]$. The fluorimetric signal was read in a microplate reader and calculated for activities of caspase- $3 / 7$.

Measurement of intracellular reactive oxygen species (ROS) levels

Intracellular ROS production was evaluated using membrane-permeable probe DCFH-DA assay as described previously [34]. HUVECs were cultured in medium of normal glucose, high glucose and high glucose + FGF21 (30 nM) for 48 hours, and then washed with PBS followed by incubation in medium containing $20 \mu \mathrm{mol} / \mathrm{L} \mathrm{DCFH-DA}$ at $37^{\circ} \mathrm{C}$ for 2 hours. Subsequently, the cell medium containing DCFH-DA was removed and washed with PBS for three times. Then, the fluorescence was revealed by fluorescence microscopy. The DCFH-DA fluorescence was calculated using Image Pro Plus software (Media Cybernetics, Silver Spring, USA).

MDA levels and activities of Mn-SOD and $\mathrm{Cu} / \mathrm{Zn}-\mathrm{SOD}$

Intracellular lipid peroxidation was evaluated by measurement of MDA levels as described previously [35]. Anti-oxidant activity was evaluated by measurement of Mn-SOD and Cu/Zn-SOD activities as described previously [36]. Briefly, the HUVECs incubated with normal glucose, high glucose and high glucose + FGF21 ( $30 \mathrm{nM}$ ) for 24 and 48 hours were lysed by RIPA buffer, and then the Mn-SOD and Cu/Zn-SOD activities and intracellular MDA concentrations of each sample were detected according to the manufacturer's instruction using microplate reader respectively.

\section{NO production measurement}

The concentration of NO in HUVECs was determined as described previously [37]. The concentration of nitrite, the stable product of NO was detected to reflect the NO production. HUVECs were incubated with medium of normal glucose, high glucose and high glucose + FGF21 (30 nM) for 24 and 48 hours. The medium was collected and nitrite content in the medium was measured using a microplate method based on the Griess reaction. The optical densities at $560 \mathrm{~nm}$ wavelength were obtained using a Microplate Reader (Thermo, USA) and concentrations of NO were calculated according to the calibration curve.

\section{Intracellular cGMP measurement}

HUVECs were treated with normal glucose, high glucose and high glucose + FGF21 (30 nM) for 12 hours and 24 hours. Then, cells were lysed by RIPA buffer with same volume. Protein concentration was determined by BCA assay. Protein concentration of all samples was adjusted to be equal. The cGMP level was measured using a commercial cGMP ELISA kit according to the manufacturer's instruction.

\section{Statistical analysis}

Statistical analysis was performed using the GraphPad Prism 5 software program. The data were expressed as the mean \pm SEM and compared using ANOVA with Tukey correction. Statistical significance was set at $P<0.05$.

\section{Results}

$\beta$-klotho, the essential anchor protein for FGF21 function, is expressed in HUVECs

As shown in Fig. 1A, immunofluorescence staining with primary antibody against $\beta$-klotho showed that $\beta$-klotho was indeed expressed in HUVECs. In contrast, there was no detectable immunofluorescence signal in negative control experiments with nonspecific normal IgG. We also performed Western Blotting analysis using two primary 


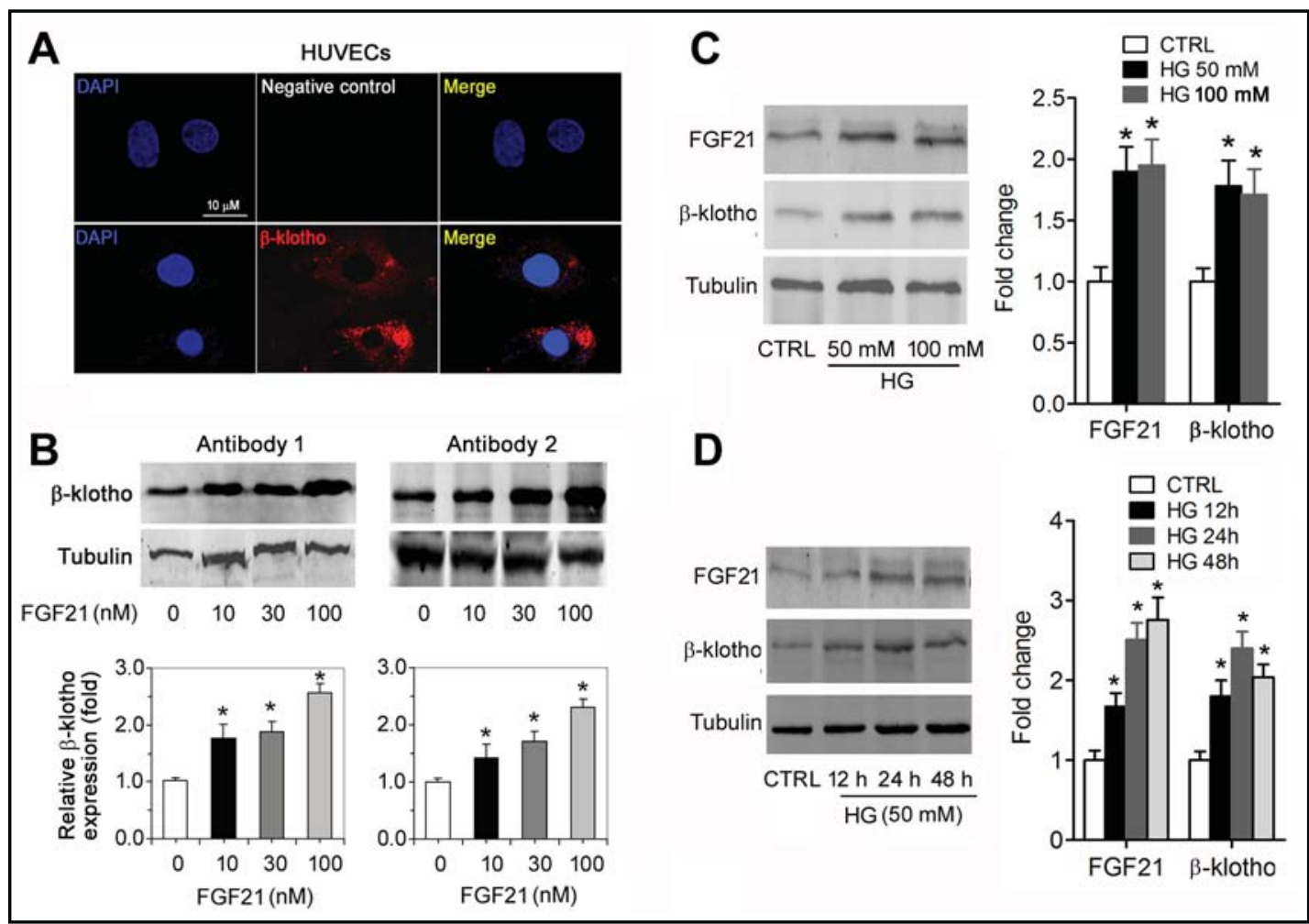

Fig. 1. $\beta$-klotho is expressed in HUVECs. (A) Immunofluorescence staining of $\beta$-klotho in HUVECs. Cell were fixed by $4 \%$ paraformalin and stained by anti- $\beta$-klotho antibody or negative control and followed by Cy3conjugated secondary antibody. The samples of negative control were treated in the same way but incubated with normal IgG in stead of anti- $\beta$-klotho. DAPI was used to stain nucleus. The images were captured suing FV1000 confocal microscopy. (B) Effects of three concentrations of FGF21 (10, 30 and $100 \mathrm{nM}$ ) on $\beta$-klotho protein expression was determined by Western Blotting using two primary antibodies (Antibody 1: ab106794 from Abcam; Antibody 2: sc-74343 from Santa Cruz Biotechnology). Tubulin was used as a loading control. $* \mathrm{P}<0.05$ vs without $\mathrm{FGF} 21, \mathrm{~N}=4$. (C) Effects of high glucose $(50 \mathrm{mM}$ and $100 \mathrm{mM}$ ) on protein expressions of FGF21 and $\beta$-klotho. ${ }^{*} \mathrm{P}<0.05$ vs control, $\mathrm{N}=5$ per group. (D) Effects of high glucose ( $50 \mathrm{mM}$ ) incubation for 12, 24 and 48 hours on protein expressions of FGF2 1 and $\beta$-klotho. ${ }^{*} \mathrm{P}<0.05$ vs control, $\mathrm{N}=$ 5 per group.

antibodies (Antibody 1: AF5889 from R\&D Systems; Antibody 2: sc-74343 from Santa Cruz Biotechnology). Both of these two antibodies were able to detect $\beta$-klotho protein in HUVECs (Fig. 1B). Moreover, FGF21 treatment (10, 30 and $100 \mathrm{nM}$ ) enhanced $\beta$-klotho protein expression in HUVECs in a dose-dependent manner (Fig. 1B). Two concentrations of high glucose ( $50 \mathrm{mM}$ and $100 \mathrm{mM}$ ) upregulated protein expression of FGF21 and $\beta$-klotho (Fig. 1C). There was no significant difference between $50 \mathrm{mM}$ and $100 \mathrm{mM}$ glucose (Fig. 1C). So we used $50 \mathrm{mM}$ glucose in the following experiments. Treatment of high glucose (50 $\mathrm{mM}$ ) upregulated protein expression of FGF21 and $\beta$-klotho in a time-dependent manner (Fig. 1D). These results demonstrate that $\beta$-klotho, the essential anchor protein of FGF21 biological function, is expressed in HUVECs. In the following experiments, we used $30 \mathrm{nM}$ FGF21 to treat cells because the 30 nM FGF21 was sufficient to induce $\beta$-Klotho expression.

FGF21 protects against high glucose-induced damage in HUVECS

Next, we determined whether FGF21 had biological functions on HUVECs under high glucose condition stresscondition. High glucose challenge for 24 and 48 hours decreased cell viability by about 20\% in HUVECs (Fig. 2A). FGF21 administration (30 nM) significantly attenuated this damage (Fig. 2A). Similarly, high glucose decreased cell migration of HUVECs, 


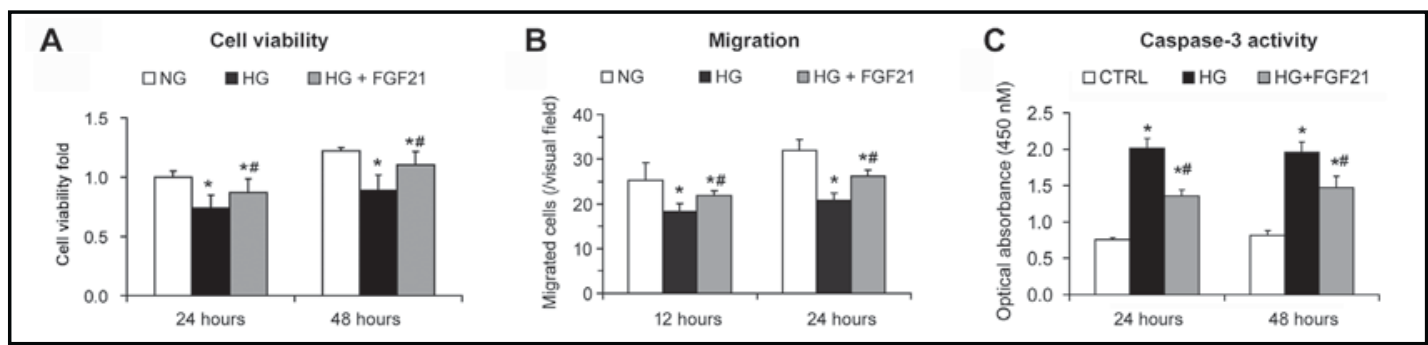

Fig. 2. FGF21 protects against high glucose-induced cell damage in HUVECs. (A) Effects of high glucose and FGF21 on the cell viability of HUVECs. Cells were treated with medium of normal glucose (NG, $5.5 \mathrm{mM}$ ), high glucose (HG, $50 \mathrm{mM}$ ) and HG plus FGF21 (30 nM) for 24 hours or 48 hours, and then cell viability was measured using CCK-8 kit. ${ }^{*} \mathrm{P}<0.05$ vs $\mathrm{NG}$, ${ }^{\mathrm{P}}<0.05$ vs HG, $\mathrm{N}=6$. (B) Effects of high glucose and FGF21 on the migration of HUVECs. HUVECs $\left(1 \times 10^{5}\right)$ were placed in the upper chamber of a 24 -well transwell migration insert with medium of NG, HG and HG + FGF21 (30 nM). The lower chamber contained migration medium to induce HUVECs migration for 12 or 24 hours. ${ }^{*} \mathrm{P}<0.05$ vs NG, ${ }^{*} \mathrm{P}<0.05$ vs HG, $\mathrm{N}=8$. (C) Effects of high glucose and FGF21 on the caspas- 3 activity of HUVECs. ${ }^{*} \mathrm{P}<0.05$ vs NG, ${ }^{*} \mathrm{P}<0.05$ vs HG, $\mathrm{N}=5$.

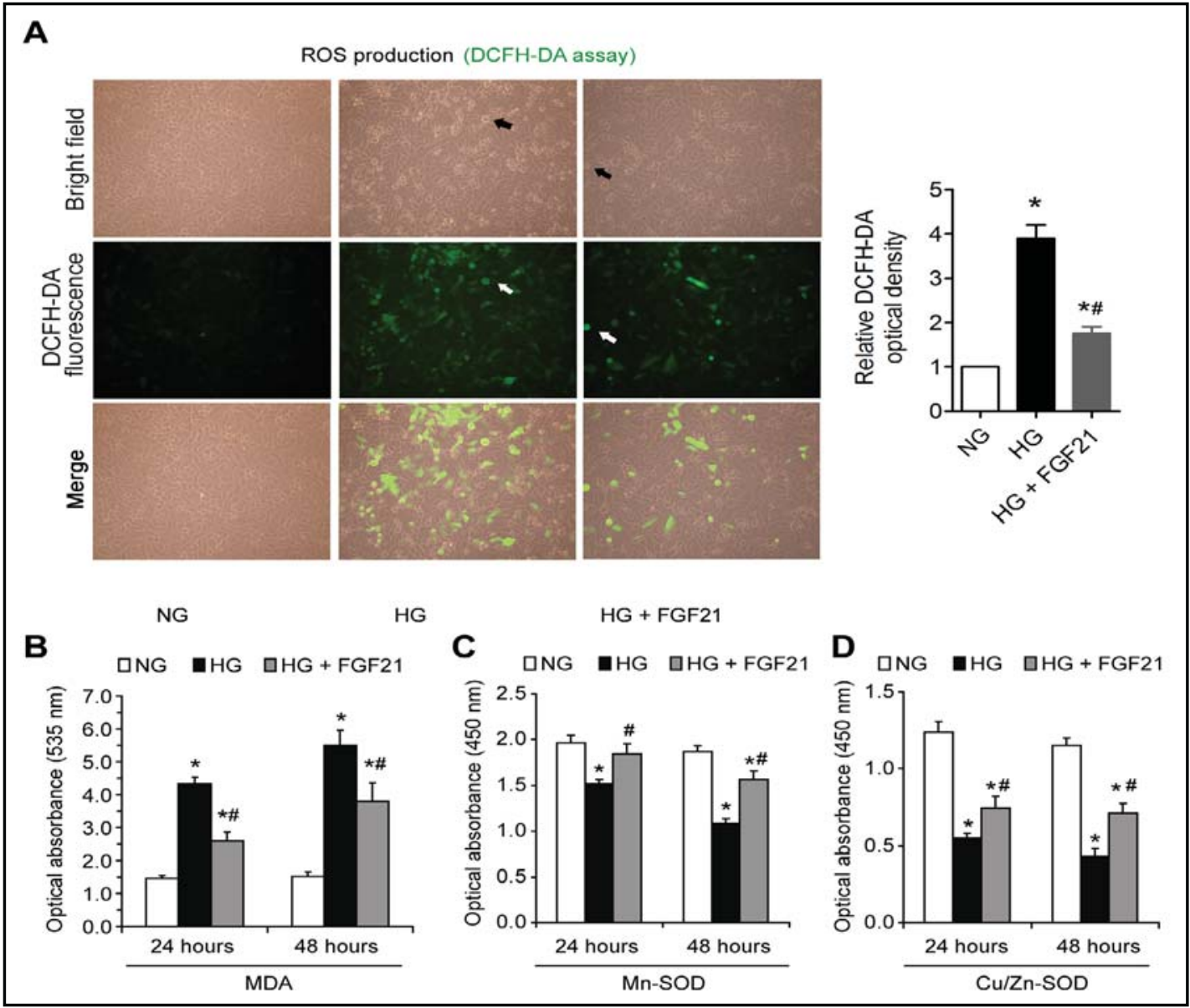

Fig. 3. FGF21 decreases high glucose-induced oxidant stress in HUVECs. (A) Representative images and quantitative analysis of DCFH-DA fluorescence in HUVECs treated with normal glucose (NG, $5.5 \mathrm{mM}$ ), high glucose (HG, $50 \mathrm{mM}$ ) and HG + FGF21 (30 nM) for 24 hours. ${ }^{*} \mathrm{P}<0.05 \mathrm{vs} \mathrm{NG,}{ }^{\mathrm{P}}<0.05 \mathrm{vs} \mathrm{HG}, \mathrm{N}=8$. (B-D) Intracellular MDA levels (B), Mn-SOD activities (C) and Cu/Zn-SOD activities (D) in HUVECs treated with NG, HG and HG + FGF21 (30 nM) for 24 or 48 hours. ${ }^{*} \mathrm{P}<0.05$ vs NG, ${ }^{~} \mathrm{P}<0.05$ vs HG, N = 6.

which was partly abolished by FGF21 administration (Fig. 2B). High glucose also increased activities of caspase-3/7, two key pro-apoptotic factors. FGF21 significantly decreased the 
A

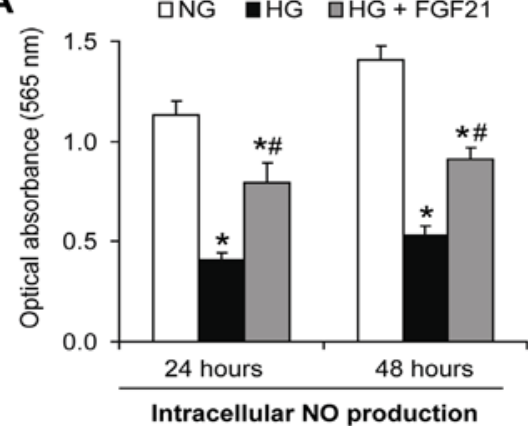

B

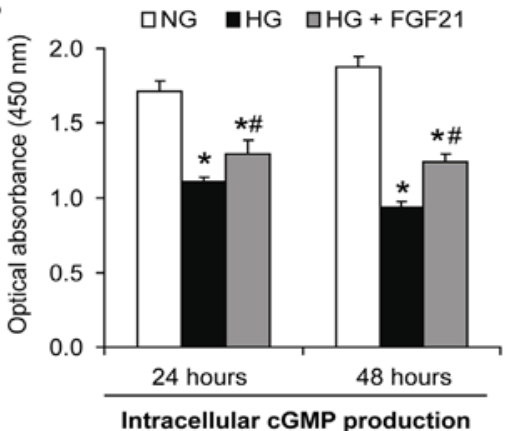

Fig. 4. FGF21 prevents high glucose-induced inhibition of NO production and cGMP levels in HUVECs. (A) NO production in the culture medium of HUVECs treated with normal glucose (NG, $5.5 \mathrm{mM})$, high glucose (HG, $50 \mathrm{mM}$ ) and HG + FGF21 (30 nM) for 24 or 48 hours. ${ }^{*} \mathrm{P}<0.05 \mathrm{vs} \mathrm{NG,}{ }^{*} \mathrm{P}<0.05 \mathrm{vs} \mathrm{HG}, \mathrm{N}=6$. (B) Intracellular cGMP levels in HUVECs treated with NG, HG and HG + FGF21 (30 nM) for 24 or 48 hours. *P $<0.05$ vs $\mathrm{NG},{ }^{\#} \mathrm{P}<0.05$ vs $\mathrm{HG}, \mathrm{N}=6$.

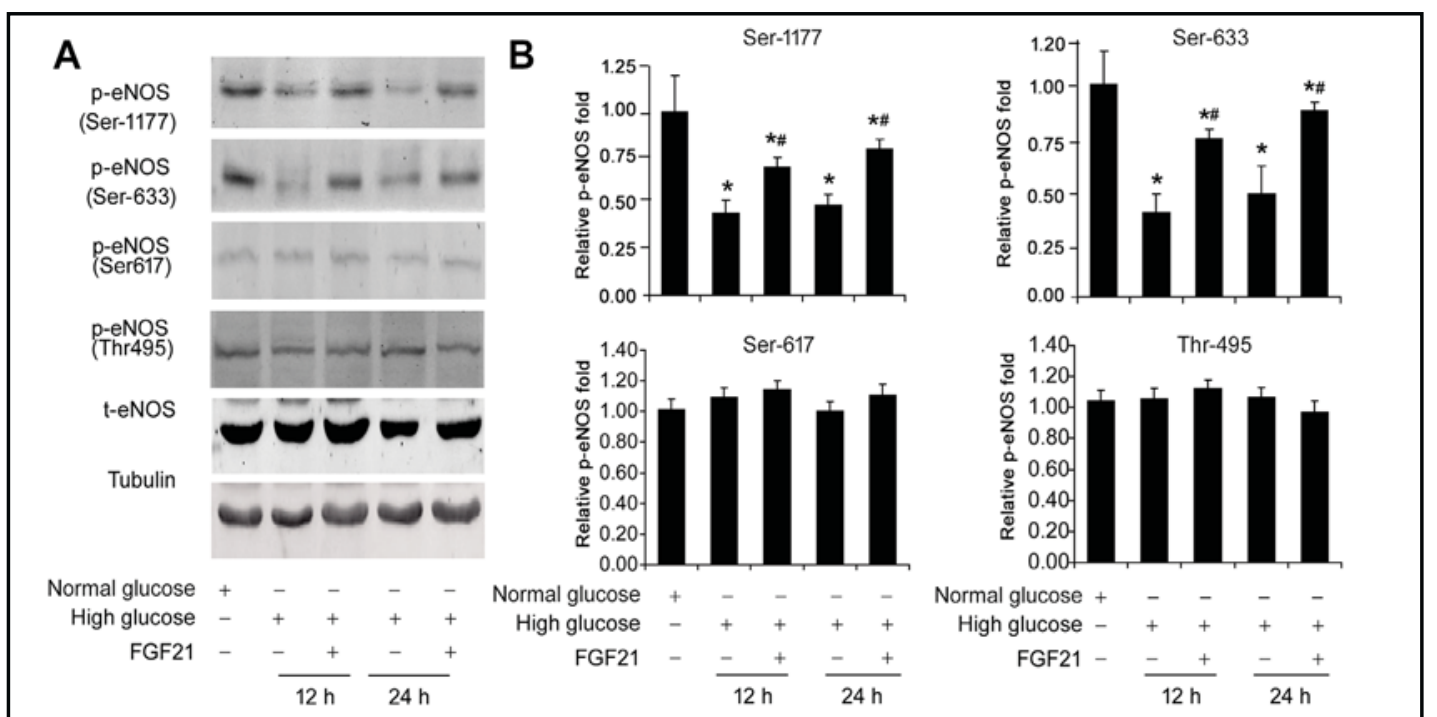

Fig. 5. FGF21 rescues high glucose-induced dysfunction of eNOS phosphorylation in HUVECs. (A) Representative images for Western blotting analysis of eNOS phosphorylation at Ser-1177, Ser-633, Ser-617 and Thr-495 sites in HUVECs treated with normal glucose (NG, $5.5 \mathrm{mM}$ ), high glucose (HG, $50 \mathrm{mM}$ ) and HG + FGF21 (30 nM) for 12 or 24 hours. (B) Quantitative analysis of eNOS phosphorylation at Ser-1177, Ser-633, Ser-617 and Thr-495 sites in HUVECs. ${ }^{*} \mathrm{P}<0.05$ vs NG, ${ }^{\#} \mathrm{P}<0.05$ vs HG, N $=6$.

upregulation of caspase-3/7 activities (Fig. 2C). These results demonstrate the cytoprotective effect of FGF21 against high glucose-induced damage in endothelial cells.

FGF21 decreased high glucose-induced oxidant stress in HUVECS

We next studied the effects of FGF21 on high glucose-induced damage oxidant stress in HUVECs. DCFH-DA assay demonstrated that high glucose treatment triggered fluorescence in HUVECs, suggesting that ROS level in HUVECs was remarkably enhanced in high glucose culture (Fig. 3A). Supplement of FGF21 (30 nM) significantly lowered the DCFHDA fluorescence (Fig. 3A). We also measured MDA level, which is an index of endogenous lipid peroxidation. High glucose significantly elevated MDA level in HUVECs (Fig. 3B), which was also partly inhibited by FGF21 treatment (Fig. 3B). In contrast, the activities of Mn-SOD and $\mathrm{Cu} / \mathrm{Zn}-\mathrm{SOD}$, two major scavengers of ROS, were decreased by high glucose (Fig. 3C-3D). 
Fig. 6. The protection of FGF21 on eNOS phosphorylation in HUVECs is AMPK-dependent. (A-B) Representative images (A) and quantitative analysis (B) of eNOS phosphorylation at Ser-1177 site in HUVECs treated with normal glucose (NG, $5.5 \mathrm{mM}$ ), high glucose (HG, $50 \mathrm{mM}$ ) and HG + FGF21 (30 nM) for 12 hours under MK2206 (20 nM), KN-93 (5 $\mu \mathrm{M})$ and compound $\mathrm{C}$ $(20 \mu \mathrm{M})$. MK-2206 is a specific inhibitor of Akt pathway. KN-93 is a specific inhibitor of CaMKII pathway. Compound $\mathrm{C}$ is a specific inhibitor of AMPK pathway. ${ }^{*} \mathrm{P}<0.05$ vs NG. NS, no significance.

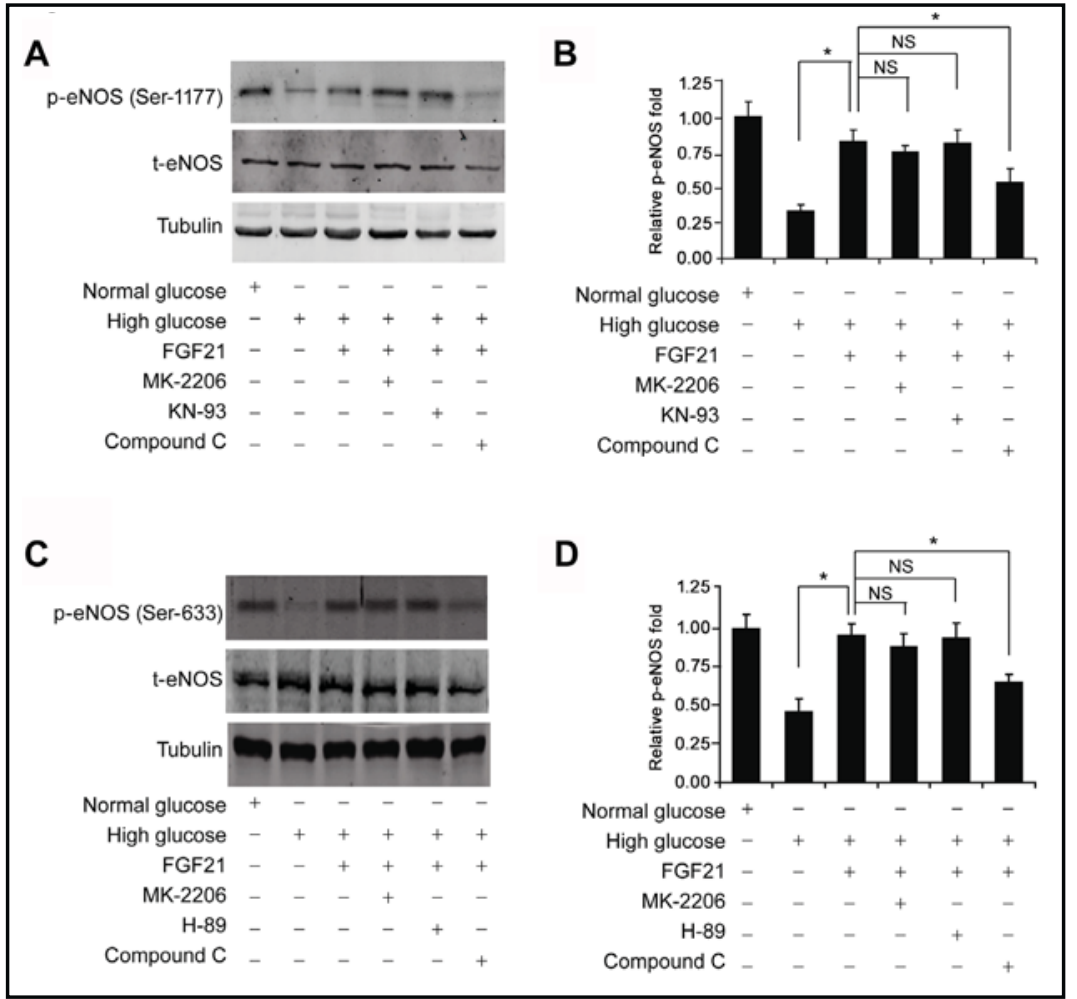

$\mathrm{N}=6$. (C-D) Representative images (C) and quantitative analysis (D) of eNOS phosphorylation at Ser-633 site in HUVECs treated with normal glucose (NG, $5.5 \mathrm{mM}$ ), high glucose (HG, $50 \mathrm{mM})$ and HG + FGF21 (30 $\mathrm{nM})$ for 12 hours under MK-2206 (20 nM), H-89 $(20 \mu \mathrm{M})$ and compound C (20 $\mu \mathrm{M})$. MK-2206 is a specific inhibitor of Akt pathway. $\mathrm{H}-89$ is a specific inhibitor of PKA pathway. Compound $\mathrm{C}$ is a specific inhibitor of AMPK pathway. ${ }^{*} \mathrm{P}<0.05$ vs NG. NS, no significance. $\mathrm{N}=6$.

FGF21 treatment partly attenuated these effects (Fig. 3C-3D). All these results suggest that FGF21 is able to decrease high glucose-induced oxidant stress in HUVECs.

FGF21 rescues high glucose-impaired NO production in HUVECs

$\mathrm{NO}$ is the key endothelium-derived relaxing factor that plays a pivotal role in the maintenance of vascular tone and reactivity, which is one of the most important functions of endothelial cells [38, 39]. We studied the effects of FGF21 on NO production in HUVECs upon high glucose stress. As shown in Fig. 4A, high glucose treatment for 24 and 48 hours significantly reduced the NO production of HUVECs. Interestingly, FGF21 treatment (30 nM) partly reversed this reduction (Fig. 4A). We also assayed the levels of intracellular cGMP, which is produced by soluble guanylyl cyclases in responding to NO and thus represents an important index for NO production. We found that cGMP levels in HUVECs was significantly decreased by high glucose, which was also partly prevented by FGF21 (Fig. 4B). These results indicate that FGF21 partly rescues high glucose-induced impairment on NO production in HUVECs.

FGF21 prevents high glucose-induced inhibition of eNOS phosphorylation

eNOS, the rate-limiting enzyme for endothelial NO production, is critical for biological activity of endothelial cells, especially under high glucose stress [40]. We measured the influence of FGF21 on eNOS protein expression. High glucose did not alter total eNOS protein expression (Fig. 5A). However, high glucose significantly decreased eNOS phosphorylation at Ser-1177 (Fig. 5A and 5B) and Ser-633 (Fig. 5A and 5B), two positive regulatory sites for eNOS enzymatic activity. FGF21 treatment significantly prevented the high glucoseinduced decrease of eNOS phosphorylation at Ser-1177 and Ser-633 sites partly in HUVECs 
Fig. 7. FGF21 activates AMPK signaling in HUVECs. Representative image and quantitative analysis of AMPK signaling activation in FGF21-treated HUVECs. ${ }^{*} \mathrm{P}<0.05$ vs CTRL. $\mathrm{N}=4$.

(Fig. 5A-5B). By contrast, high glucose and FGF21 had no effects on Ser-617 and Thr-495 sites of eNOS phosphorylation (Fig. 5A-5B).

AMPK signaling pathwaymediates the regulatory effects of FGF21 on phosphorylation of eNOS in HUVECS

Phosphorylation of eNOS on multiple-sites was regulated by complex signaling pathways [41]. We used specific chemical inhibitors to explore which molecular signaling pathway is involved in the increase of eNOS phosphorylation by FGF21 treatment. As shown in Fig. 6A and 6B, FGF21 (lane 3) rescued the Ser-1177 phosphorylation of eNOS under high glucose stress. Treatment of $\mathrm{Ca}^{2+} /$ calmodulin-dependent protein kinase II (CaMKII) pathway inhibitor KN-93 or Akt pathway MK-2206 had no influence on this protective effect of FGF21 in HUVECs. However, treatment of compound C, an inhibitor of AMP-activated protein kinase (AMPK) pathway, partly impaired this effect of FGF21. Similarly, the rescued Ser-633 phosphorylation of eNOS by FGF21 (lane 3) under high glucose stress was also abolished by compound C (AMPK pathway inhibitor) rather than PKA pathway inhibiotr H-89 or Akt pathway inhibitor MK-2206 (Fig. 6C-6D). Indeed, FGF21 activated AMPK signaling in HUVECs (Fig. 7). Knockdown of AMPK $\alpha 1 / 2$ isoforms by siRNA (Fig. 8A) partly inhibited the protective effect of FGF21 on eNOS phosphorylation of Ser-1177 (Fig. 8B and 8C) and Ser-633 sites (Fig. 8B and 8D). All these results suggest that AMPK signaling pathway is required for the regulatory effects of FGF21 on phosphorylation of eNOS in HUVECs.

\section{Discussion}

In the present study, we demonstrated that $\beta$-klotho is expressed in endothelial cells, suggesting FGF21 may act on endothelial functions. We found that administration of FGF21 potently protects against high glucose-induced decrease of cell viability and migration, decreased high glucose-induced oxidant stress, prevented high glucose-induced decrease of eNOS phosphorylation in HUVECs. Furthermore, inhibition of AMPK signaling pathway effectively abolished the protective effect of FGF21 on eNOS phosphorylation in HUVECs. These data suggests that FGF21 may be an important contributor in endothelial fucntions.

The first important finding of our study is that we found $\beta$-klotho is expressed in endothelial cells. For a long time, FGF21 was thought to be a hormone whose biological effects was restricted in metabolism system [9] due to the restricted expression of $\beta$-klotho [8]. Whereas the receptors of FGF21 are broadly expressed, $\beta$-klotho, the essential anchor protein for FGF21, is expressed in a more select set of tissues that include liver, white adipose tissue, pancreas, and testes $[8,10]$. In adult mice, $\beta$-klotho mRNA was predominantly expressed in the liver and pancreas, with lower levels in skin, and weakly in the stomach, skeletal muscle, small intestine and lung [8]. According to our knowledge, there was no available literature about $\beta$-klotho expression in blood vessel. In this study, we for the first time reported that $\beta$-klotho is expressed in endothelial cells, which suggests that FGF21 may directly act on endothelial cells.

Blood FGF21 levels were elevated in diabetic patients and correlates with insulin resistance $[20,21]$. In addition, a previous study showed that state of obesity and insulin 
Fig. 8. Knockdown of AMPK $\alpha 1 / 2$ isoforms partly inhibits the protective effect of FGF21 on eNOS phosphorylation. (A) siRNA-mediated knockdown of AMPK $\alpha 1 / 2$. ${ }^{*} \mathrm{P}$ $<0.05$ vs siRNA-control. $\mathrm{N}=4$. (B) Representative images of eNOS phosphorylation at Ser1177 and Ser-633 sites in HUVEC with siRNA-AMPK $\alpha 1 / 2$. (C-D) Quantitative analysis of eNOS phosphorylation at Ser1177 (C) and Ser-633 (D) sites. ${ }^{*} \mathrm{P}<0.05$ vs without FGF21. "P $<0.05$ vs siRNA-control. $\mathrm{N}=4$.
A
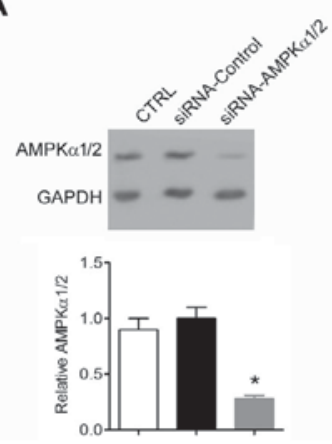

C

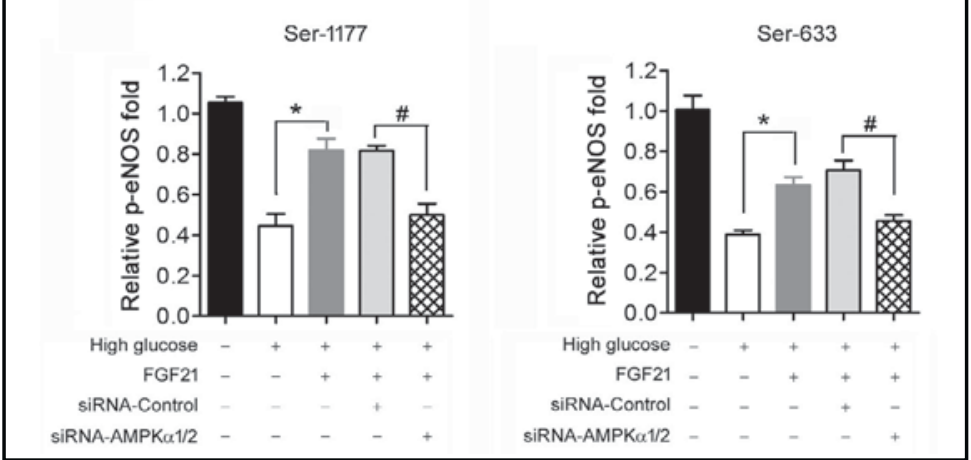

Fig. 9. A working model of the FGF21-induced protection on endothelial cells against high-glucose stress.

resistance has increased endogenous levels of FGF21 and respond poorly to exogenous FGF21 [42], whereas two other groups suggest a compensatory response [43, 44]. These reports indicate that FGF21 is linked to metabolic and vascular risk factors. However, the cause of the increment of serum FGF21 and its impacts on cardiovascular tissues remain to be determined. It is well known that endothelial dysfunction plays a crucial

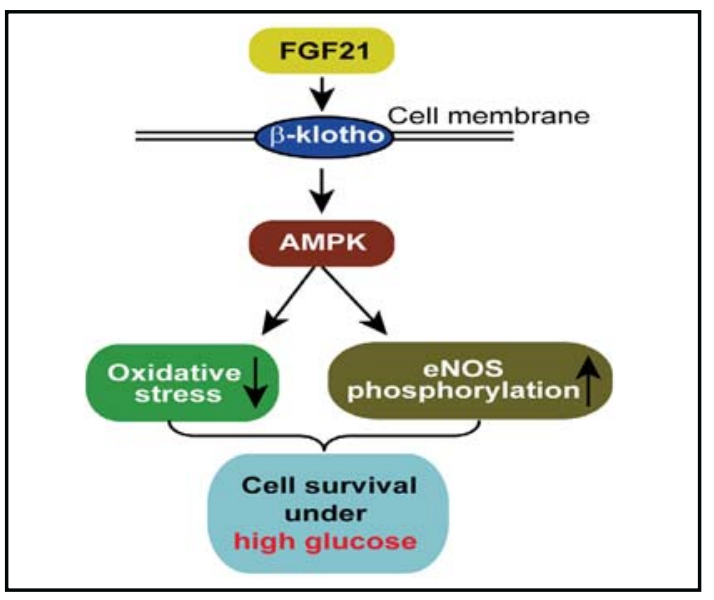
role in the pathogenesis of diabetic vascular complications [34, 40, 45-49]. High glucose condition increases NADPH oxidase activity in endothelial microparticles that promote vascular inflammation [50]. FGF21 increased LDL-R expression and mediated beneficial effect on cholesterol uptake, which was additive by statin [51]. Because statin has potent end othelial protection $[52,53]$, the association between FGF21 and endothelial function is a rather interesting question. We determined the biological functions of FGF21 on endothelial cells. High glucose induced apoptosis and autophagy, which is associated with cell death $[54,55]$. Upon high glucose stress, FGF21 displayed cytoprotection, evidence by results from cell viability and migration. FGF21 also decreased the high glucose-induced oxidative stress. Finally, and may be most importantly, FGF21 rescued the reduction of phosphorylation of eNOS and NO production, which is a central controller of vascular functions and biology. Our data indicate that FGF21 may be a promising target in the treatment of vascular complications of hyperglycaemia or diabetes mellitus.

We found that FGF21 reversed the phosphorylation on Ser-1177 and Ser-633 sites of eNOS decreased by high glucose. No effects on Ser-617 and Thr-495 were observed. 


\section{Cellular Physiology and Biochemistry}

Cell Physiol Biochem 2014;34:658-671

\begin{tabular}{l|l}
\hline DOI: $10.1159 / 000363031$ & (C) 2014 S. Karger AG, Basel
\end{tabular}

www.karger.com/cpb

Wang et al.: Effect of FGF21 on ECs Under High Glucose Condition

The roles of eNOS in endothelial functions are extensively studied. Ser-1177 and Ser-633 sites are two positive regulatory sites for eNOS enzymatic activity [41, 56]. Ser-1177 site of eNOS is phosphorylated by Akt [57], CaMKII [58], and AMPK [59]. Ser-633 of eNOS is phosphorylated by Akt [57], cAMP-dependent protein kinase A (PKA) [60] and AMPK [61]. The phosphorylation of eNOS also plays important roles in other pathophysiological process such as myocardial infarction and vascular insulin sensitivity [62-64]. To explore how FGF21 regulates these two sites phosphorylation, we used chemical inhibitors to selectively block these signaling pathways. Only inhibitor of AMPK partly blocked the protective effect of FGF21 on Ser-1177 and Ser-633 sites of eNOS phosphorylation. Previously, FGF21 was reported to increase AMPK Thr-172 phosphorylation in vitro and in vivo, resulting in enhanced mitochondrial oxidative function in adipocytes [65]. AMPK is a energy sensor that maintains energy homeostasis [66] and is involved in survival and autophagy under diabetic condition $[67,68]$. FGF21 activated AMPK and induced cardiac protection on cardiac function in rodent hearts [69]. FGF21 is also correlated with AMPK activation and underlies the glucagon and lipid interactions in liver [70]. Furthermore, AMPK was indispensable for the induction of FGF21 by metformin in hepatocytes [71]. Our results are in line with these reports, suggesting that AMPK is critical for the eNOS regulation of FGF21 in endothelial cells.

In conclusion, our results provide the first evidence that FGF21 can act on endothelial cells. Under high glucose challenge, FGF21 protects against cellular damage and eNOS dysfunction in endothelial cells. AMPK signaling pathway is required for the regulatory effects of FGF21 on eNOS phosphorylation. Thus, our results suggest the potential therapeutic effect of FGF21 in diabetes-related vascular complications.

\section{Acknowledgment}

This work was supported by National Natural Science Foundation of China (Number: 81370446).

\section{Disclosure Statement}

None.

\section{References}

1 van den Oever IA, Raterman HG, Nurmohamed MT, Simsek S: Endothelial dysfunction, inflammation, and apoptosis in diabetes mellitus. Mediators Inflamm 2010;2010:792393.

2 Chen ML, Yi L, Jin X, Liang XY, Zhou Y, Zhang T, Xie Q, Zhou X, Chang H, Fu YJ, Zhu JD, Zhang QY, Mi MT: Resveratrol attenuates vascular endothelial inflammation by inducing autophagy through the cAMP signaling pathway. Autophagy 2013;9:2033-2045.

-3 Han J, Pan XY, Xu Y, Xiao Y, An Y, Tie L, Pan Y, Li XJ: Curcumin induces autophagy to protect vascular endothelial cell survival from oxidative stress damage. Autophagy 2012;8:812-825.

-4 Hink U, Li H, Mollnau H, Oelze M, Matheis E, Hartmann M, Skatchkov M, Thaiss F, Stahl RA, Warnholtz A, Meinertz T, Griendling K, Harrison DG, Forstermann U, Munzel T: Mechanisms underlying endothelial dysfunction in diabetes mellitus. Circ Res 2001;88:E14-22.

5 Meigs JB, Hu FB, Rifai N, Manson JE: Biomarkers of endothelial dysfunction and risk of type 2 diabetes mellitus. JAMA 2004;291:1978-1986.

6 Itoh N, Ornitz DM: Fibroblast growth factors: from molecular evolution to roles in development, metabolism and disease. J Biochem 2011;149:121-130.

7 Zhang J, Liu J, Liu L, McKeehan WL, Wang F: The fibroblast growth factor signaling axis controls cardiac stem cell differentiation through regulating autophagy. Autophagy 2012;8:690-691.

Ito S, Kinoshita S, Shiraishi N, Nakagawa S, Sekine S, Fujimori T, Nabeshima YI: Molecular cloning and expression analyses of mouse betaklotho, which encodes a novel Klotho family protein. Mech Dev 2000;98:115-119. 


\section{Cellular Physiology and Biochemistry}

Cell Physiol Biochem 2014;34:658-671

\begin{tabular}{l|l}
\hline DOI: $10.1159 / 000363031$ & (c) 2014 S. Karger AG, Basel
\end{tabular}

www.karger.com/cpb

Wang et al.: Effect of FGF21 on ECs Under High Glucose Condition

-9 Cuevas-Ramos D, Aguilar-Salinas CA, Gomez-Perez FJ: Metabolic actions of fibroblast growth factor 21. Curr Opin Pediatr 2012;24:523-529.

10 Ogawa Y, Kurosu H, Yamamoto M, Nandi A, Rosenblatt KP, Goetz R, Eliseenkova AV, Mohammadi M, Kuro-o M: BetaKlotho is required for metabolic activity of fibroblast growth factor 21. Proc Natl Acad Sci U S A 2007;104:7432-7437.

-11 Inagaki T, Dutchak P, Zhao G, Ding X, Gautron L, Parameswara V, Li Y, Goetz R, Mohammadi M, Esser V, Elmquist JK, Gerard RD, Burgess SC, Hammer RE, Mangelsdorf DJ, Kliewer SA: Endocrine regulation of the fasting response by PPARalpha-mediated induction of fibroblast growth factor 21. Cell Metab 2007;5:415425.

12 Ro SH, Jung CH, Hahn WS, Xu X, Kim YM, Yun YS, Park JM, Kim KH, Seo M, Ha TY, Arriaga EA, Bernlohr DA, Kim DH: Distinct functions of Ulk1 and Ulk2 in the regulation of lipid metabolism in adipocytes. Autophagy 2013;9:2103-2114.

13 Dutchak PA, Katafuchi T, Bookout AL, Choi JH, Yu RT, Mangelsdorf DJ, Kliewer SA: Fibroblast growth factor-21 regulates PPARgamma activity and the antidiabetic actions of thiazolidinediones. Cell 2012;148:556-567.

14 Badman MK, Pissios P, Kennedy AR, Koukos G, Flier JS, Maratos-Flier E: Hepatic fibroblast growth factor 21 is regulated by PPARalpha and is a key mediator of hepatic lipid metabolism in ketotic states. Cell Metab 2007;5:426-437.

15 Wente W, Efanov AM, Brenner M, Kharitonenkov A, Koster A, Sandusky GE, Sewing S, Treinies I, Zitzer H, Gromada J: Fibroblast growth factor-21 improves pancreatic beta-cell function and survival by activation of extracellular signal-regulated kinase 1/2 and Akt signaling pathways. Diabetes 2006;55:2470-2478.

16 Hotta Y, Nakamura H, Konishi M, Murata Y, Takagi H, Matsumura S, Inoue K, Fushiki T, Itoh N: Fibroblast growth factor 21 regulates lipolysis in white adipose tissue but is not required for ketogenesis and triglyceride clearance in liver. Endocrinology 2009;150:4625-4633.

-17 Bookout AL, de Groot MH, Owen BM, Lee S, Gautron L, Lawrence HL, Ding X, Elmquist JK, Takahashi JS, Mangelsdorf DJ, Kliewer SA: FGF21 regulates metabolism and circadian behavior by acting on the nervous system. Nat Med 2013;19:1147-1152.

-18 Owen BM, Bookout AL, Ding X, Lin VY, Atkin SD, Gautron L, Kliewer SA, Mangelsdorf DJ: FGF21 contributes to neuroendocrine control of female reproduction. Nat Med 2013;19:1153-1156.

-19 Payne BA, Price DA, Chinnery PF: Elevated serum fibroblast growth factor 21 levels correlate with immune recovery but not mitochondrial dysfunction in HIV infection. AIDS Res Ther 2013;10:27.

20 Chavez AO, Molina-Carrion M, Abdul-Ghani MA, Folli F, Defronzo RA, Tripathy D: Circulating fibroblast growth factor-21 is elevated in impaired glucose tolerance and type 2 diabetes and correlates with muscle and hepatic insulin resistance. Diabetes Care 2009;32:1542-1546.

-21 Chen WW, Li L, Yang GY, Li K, Qi XY, Zhu W, Tang Y, Liu H, Boden G: Circulating FGF-21 levels in normal subjects and in newly diagnose patients with Type 2 diabetes mellitus. Exp Clin Endocrinol Diabetes 2008;116:65-68.

22 Mahoney E, Byrd JC, Johnson AJ: Autophagy and ER stress play an essential role in the mechanism of action and drug resistance of the cyclin-dependent kinase inhibitor flavopiridol. Autophagy 2013;9:434-435.

-23 Ambjorn M, Ejlerskov P, Liu Y, Lees M, Jaattela M, Issazadeh-Navikas S: IFNB1/interferon-beta-induced autophagy in MCF-7 breast cancer cells counteracts its proapoptotic function. Autophagy 2013;9:287-302.

-24 Kley RA, van der Ven PF, Olive M, Hohfeld J, Goldfarb LG, Furst DO, Vorgerd M: Impairment of protein degradation in myofibrillar myopathy caused by FLNC/filamin C mutations. Autophagy 2013;9:422-423.

25 Xing S, Zhang Y, Li J, Zhang J, Li Y, Dang C, Li C, Fan Y, Yu J, Pei Z, Zeng J: Beclin 1 knockdown inhibits autophagic activation and prevents the secondary neurodegenerative damage in the ipsilateral thalamus following focal cerebral infarction. Autophagy 2012;8:63-76.

-26 Zhou C, Zhong W, Zhou J, Sheng F, Fang Z, Wei Y, Chen Y, Deng X, Xia B, Lin J: Monitoring autophagic flux by an improved tandem fluorescent-tagged LC3 (mTagRFP-mWasabi-LC3) reveals that high-dose rapamycin impairs autophagic flux in cancer cells. Autophagy 2012;8:1215-1226.

-27 Song YM, Song SO, Jung YK, Kang ES, Cha BS, Lee HC, Lee BW: Dimethyl sulfoxide reduces hepatocellular lipid accumulation through autophagy induction. Autophagy 2012;8:1085-1097.

28 Oh JM, Choi EK, Carp RI, Kim YS: Oxidative stress impairs autophagic flux in prion protein-deficient hippocampal cells. Autophagy 2012;8:1448-1461.

29 Chiao MT, Cheng WY, Yang YC, Shen CC, Ko JL: Suberoylanilide hydroxamic acid (SAHA) causes tumor growth slowdown and triggers autophagy in glioblastoma stem cells. Autophagy 2013;9:1509-1526. 


\section{Cellular Physiology and Biochemistry}

Cell Physiol Biochem 2014;34:658-671

\begin{tabular}{l|l}
\hline DOI: $10.1159 / 000363031$ & (C) 2014 S. Karger AG, Basel
\end{tabular}

Wang et al.: Effect of FGF21 on ECs Under High Glucose Condition

30 Peng YF, Shi YH, Ding ZB, Ke AW, Gu CY, Hui B, Zhou J, Qiu SJ, Dai Z, Fan J: Autophagy inhibition suppresses pulmonary metastasis of HCC in mice via impairing anoikis resistance and colonization of HCC cells. Autophagy 2013;9:2056-2068.

-31 Chen JJ, Jing J, Chang H, Rong Y, Hai Y, Tang J, Zhang JL, Xu P: A sensitive and quantitative autolysosome probe for detecting autophagic activity in live and prestained fixed cells. Autophagy 2013;9:894-904.

-32 Wang Y, Martins I, Ma Y, Kepp 0, Galluzzi L, Kroemer G: Autophagy-dependent ATP release from dying cells via lysosomal exocytosis. Autophagy 2013;9:1624-1625.

-33 Houel-Renault L, Philippe L, Piquemal M, Ciapa B: Autophagy is used as a survival program in unfertilized sea urchin eggs that are destined to die by apoptosis after inactivation of MAPK1/3 (ERK2/1). Autophagy 2013;9:1527-1539.

-34 Feng YM, Jia YF, Su LY, Wang D, Lv L, Xu L, Yao YG: Decreased mitochondrial DNA copy number in the hippocampus and peripheral blood during opiate addiction is mediated by autophagy and can be salvaged by melatonin. Autophagy 2013;9:1395-1406.

-35 Schmeisser H, Fey SB, Horowitz J, Fischer ER, Balinsky CA, Miyake K, Bekisz J, Snow AL, Zoon KC: Type I interferons induce autophagy in certain human cancer cell lines. Autophagy 2013;9:683-696.

-36 Wang Y, Nartiss Y, Steipe B, McQuibban GA, Kim PK: ROS-induced mitochondrial depolarization initiates PARK2/PARKIN-dependent mitochondrial degradation by autophagy. Autophagy 2012;8:1462-1476.

37 Cauwels A, Vandendriessche B, Bultinck J, Descamps B, Rogge E, Van Nieuwenhuysen T, Sips M, Vanhove C, Brouckaert P: TLR2 activation causes no morbidity or cardiovascular failure, despite excessive systemic nitric oxide production. Cardiovasc Res 2013;100:28-35.

- 38 Zhao YD, Courtman DW, Deng Y, Kugathasan L, Zhang Q, Stewart DJ: Rescue of monocrotaline-induced pulmonary arterial hypertension using bone marrow-derived endothelial-like progenitor cells: efficacy of combined cell and eNOS gene therapy in established disease. Circ Res 2005;96:442-450.

-39 Duda DG, Fukumura D, Jain RK: Role of eNOS in neovascularization: NO for endothelial progenitor cells. Trends Mol Med 2004;10:143-145.

-40 Matsumoto S, Shimabukuro M, Fukuda D, Soeki T, Yamakawa K, Masuzaki H, Sata M: Azilsartan, an angiotensin II type 1 receptor blocker, restores endothelial function by reducing vascular inflammation and by increasing the phosphorylation ratio Ser(1177)/Thr(497) of endothelial nitric oxide synthase in diabetic mice. Cardiovasc Diabetol 2014;13:30.

-41 Mount PF, Kemp BE, Power DA: Regulation of endothelial and myocardial NO synthesis by multi-site eNOS phosphorylation. J Mol Cell Cardiol 2007;42:271-279.

42 Fisher FM, Chui PC, Antonellis PJ, Bina HA, Kharitonenkov A, Flier JS, Maratos-Flier E: Obesity is a fibroblast growth factor 21 (FGF21)-resistant state. Diabetes 2010;59:2781-2789.

43 Hale C, Chen MM, Stanislaus S, Chinookoswong N, Hager T, Wang M, Veniant MM, Xu J: Lack of overt FGF21 resistance in two mouse models of obesity and insulin resistance. Endocrinology 2012;153:69-80.

-44 Reinehr T, Woelfle J, Wunsch R, Roth CL: Fibroblast growth factor 21 (FGF-21) and its relation to obesity, metabolic syndrome, and nonalcoholic fatty liver in children: a longitudinal analysis. J Clin Endocrinol Metab 2012;97:2143-2150.

45 Munzel T, Sinning C, Post F, Warnholtz A, Schulz E: Pathophysiology, diagnosis and prognostic implications of endothelial dysfunction. Ann Med 2008;40:180-196.

-46 Velmurugan GV, Sundaresan NR, Gupta MP, White C: Defective Nrf2-dependent redox signalling contributes to microvascular dysfunction in type 2 diabetes. Cardiovasc Res 2013;100:143-150.

-47 Doyon M, Mathieu P, Moreau P: Decreased expression of gamma-carboxylase in diabetes-associated arterial stiffness: impact on matrix Gla protein. Cardiovasc Res 2013;97:331-338.

-48 Wang Y, Li YB, Yin JJ, Zhu LB, Xie GY, Pan SH: Autophagy regulates inflammation following oxidative injury in diabetes. Autophagy 2013;9:272-277.

49 Kobayashi S, Xu X, Chen K, Liang Q: Suppression of autophagy is protective in high glucose-induced cardiomyocyte injury. Autophagy 2012;8:577-592.

-50 Jansen F, Yang X, Franklin BS, Hoelscher M, Schmitz T, Bedorf J, Nickenig G, Werner N: High glucose condition increases NADPH oxidase activity in endothelial microparticles that promote vascular inflammation. Cardiovasc Res 2013;98:94-106.

-51 Do HT, Tselykh TV, Makela J, Ho TH, Olkkonen VM, Bornhauser BC, Korhonen L, Zelcer N, Lindholm D: Fibroblast growth factor-21 (FGF21) regulates low-density lipoprotein receptor (LDLR) levels in cells via the E3-ubiquitin ligase Mylip/Idol and the Canopy2 (Cnpy2)/Mylip-interacting saposin-like protein (Msap). J Biol Chem 2012;287:12602-12611. 


\section{Cellular Physiology and Biochemistry}

Cell Physiol Biochem 2014;34:658-671

DOI: $10.1159 / 000363031$

Publisned onine: August 13, 2014

C) 2014 S. Karger AG, Basel

www.karger.com/cpb

Wang et al.: Effect of FGF21 on ECs Under High Glucose Condition

52 Lee HY, Youn SW, Cho HJ, Kwon YW, Lee SW, Kim SJ, Park YB, Oh BH, Kim HS: FOXO1 impairs whereas statin protects endothelial function in diabetes through reciprocal regulation of Kruppel-like factor 2. Cardiovasc Res 2013;97:143-152.

-53 Andreadou I, Farmakis D, Prokovas E, Sigala F, Zoga A, Spyridaki K, Papalois A, Papapetropoulos A, Anastasiou-Nana M, Kremastinos DT, Iliodromitis EK: Short-term statin administration in hypercholesterolaemic rabbits resistant to postconditioning: effects on infarct size, endothelial nitric oxide synthase, and nitro-oxidative stress. Cardiovasc Res 2012;94:501-509.

54 Garg AD, Dudek AM, Ferreira GB, Verfaillie T, Vandenabeele P, Krysko DV, Mathieu C, Agostinis P: ROSinduced autophagy in cancer cells assists in evasion from determinants of immunogenic cell death. Autophagy 2013;9:1292-1307.

-55 Kim Y, Kim YS, Kim DE, Lee JS, Song JH, Kim HG, Cho DH, Jeong SY, Jin DH, Jang SJ, Seol HS, Suh YA, Lee SJ, Kim CS, Koh JY, Hwang JJ: BIX-01294 induces autophagy-associated cell death via EHMT2/G9a dysfunction and intracellular reactive oxygen species production. Autophagy 2013;9:2126-39.

-56 Dschietzig T, Brecht A, Bartsch C, Baumann G, Stangl K, Alexiou K: Relaxin improves TNF-alpha-induced endothelial dysfunction: the role of glucocorticoid receptor and phosphatidylinositol 3-kinase signalling. Cardiovasc Res 2012;95:97-107.

-57 Dimmeler S, Fleming I, Fisslthaler B, Hermann C, Busse R, Zeiher AM: Activation of nitric oxide synthase in endothelial cells by Akt-dependent phosphorylation. Nature 1999;399:601-605.

-58 Fleming I, Fisslthaler B, Dimmeler S, Kemp BE, Busse R: Phosphorylation of Thr(495) regulates Ca(2+)/ calmodulin-dependent endothelial nitric oxide synthase activity. Circ Res 2001;88:E68-75.

59 Chen Z-P, Mitchelhill KI, Michell BJ, Stapleton D, Rodriguez-Crespo I, Witters LA, Power DA, Ortiz de Montellano PR, Kemp BE: AMP-activated protein kinase phosphorylation of endothelial NO synthase. FEBS letters 1999;443:285-289.

60 Michell BJ, Harris MB, Chen ZP, Ju H, Venema VJ, Blackstone MA, Huang W, Venema RC, Kemp BE: Identification of regulatory sites of phosphorylation of the bovine endothelial nitric-oxide synthase at serine 617 and serine 635. J Biol Chem 2002;277:42344-42351.

-61 Chen Z, Peng IC, Sun W, Su MI, Hsu PH, Fu Y, Zhu Y, DeFea K, Pan S, Tsai MD, Shyy JY: AMP-activated protein kinase functionally phosphorylates endothelial nitric oxide synthase Ser633. Circ Res 2009;104:496-505.

62 Bir SC, Xiong Y, Kevil CG, Luo J: Emerging role of PKA/eNOS pathway in therapeutic angiogenesis for ischaemic tissue diseases. Cardiovasc Res 2012;95:7-18.

63 Philippova M, Joshi MB, Pfaff D, Kyriakakis E, Maslova K, Erne P, Resink TJ: T-cadherin attenuates insulindependent signalling, eNOS activation, and angiogenesis in vascular endothelial cells. Cardiovasc Res 2012;93:498-507.

64 Gotor C, Garcia I, Crespo JL, Romero LC: Sulfide as a signaling molecule in autophagy. Autophagy 2013;9:609-611.

65 Chau MD, Gao J, Yang Q, Wu Z, Gromada J: Fibroblast growth factor 21 regulates energy metabolism by activating the AMPK-SIRT1-PGC-1alpha pathway. Proc Natl Acad Sci U S A 2010;107:12553-12558.

66 Hardie DG, Ross FA, Hawley SA: AMPK: a nutrient and energy sensor that maintains energy homeostasis. Nat Rev Mol Cell Biol 2012;13:251-262.

67 Zou M-H, Xie Z: Regulation of interplay between autophagy and apoptosis in the diabetic heart. Autophagy 2013;9:624-625.

68 Wong PM, Puente C, Ganley IG, Jiang X: The ULK1 complex: sensing nutrient signals for autophagy activation. Autophagy 2013;9:124-137.

-69 Patel V, Adya R, Chen J, Ramanjaneya M, Bari MF, Bhudia SK, Hillhouse EW, Tan BK, Randeva HS: Novel Insights into the Cardio-Protective Effects of FGF21 in Lean and Obese Rat Hearts. PLoS One 2014;9:e87102.

70 Berglund ED, Kang L, Lee-Young RS, Hasenour CM, Lustig DG, Lynes SE, Donahue EP, Swift LL, Charron MJ, Wasserman DH: Glucagon and lipid interactions in the regulation of hepatic AMPK signaling and expression of PPARalpha and FGF21 transcripts in vivo. Am J Physiol Endocrinol Metab 2010;299:E607614.

71 Nygaard EB, Vienberg SG, Orskov C, Hansen HS, Andersen B: Metformin stimulates FGF21 expression in primary hepatocytes. Exp Diabetes Res 2012;2012:465282. 